\title{
Identification of ideal size and drivers for consumer acceptability of apple
}

\author{
Hee-Yeon Jung, Sang-Sook Kim* \\ Food Distribution System Research Group, Korea Food Research Institute, Seongnam 463-746, Korea
}

\section{사과의 이상적인 크기와 소비자 기호도 결정인자 분석}

\author{
정희연 · 김상숙* \\ 한국식품연구원 유통시스템연구단
}

\begin{abstract}
The physicochemical characteristics and consumer perceptions of two Fuji cultivars (Fuji and Royal Fuji) with six different size groups (3D: 30 39, 4D: 40 49, 5D: 50 59, 6D: 60 69, 7D: 70 79, and 8D: 80 89 apples/15 kg) were investigated to identify the ideal size and the drivers of consumer acceptability of apples. For the physicochemical characteristics, the weight, volume, specific volume, $\mathrm{L}$, a, and b colors, hardness, $\mathrm{pH}$, acidity, and brix of apples were measured. A total of $\mathbf{1 0 0}$ consumers were asked to mark the intensity of the characteristics (size, redness, glossiness, surface roughness, apple odor, apple flavor, sweetness, sourness, hardness, crunchiness, and toughness) to determine the ideal characteristics of apples before they were asked to taste the apple products. The consumers evaluated the apple samples in terms of their appearance, odor, flavor, texture, and overall acceptability; the consumers' intent to purchase such apples and willingness to pay for them; and the intensity of the aforementioned characteristics. Compared to the ideal characteristics of apples, the actual apple samples were rated low in their apple odor, apple flavor, acidity, sweetness, hardness, and crispness. The ideal size of the apples was between 4D and 5D. Their overall acceptability was highly affected by their flavor, followed by their texture, odor, and appearance. The acceptability of the appearance was highly correlated with the glossiness $(r=0.80)$, volume, weight, redness $(r=0.73)$, and size $(r=0.72)$. The consumer acceptability of the apples increased with the decreased pH and the increased Brix, hardness, and color b values of the peeled apples. The apple flavor, sweetness, hardness, crispiness, juiciness, and toughness during mastication were noted as sensory drivers of consumer acceptability.
\end{abstract}

Key words : apple, ideal size, driver for consumer acceptability, sensory attributes

\section{서 론}

사과는 배, 귤과 함께 우리나라에서 가장 많이 재배되는 과일로(1), 주로 생과 형태로 소비되고 있다(2). 농림축산식 품부 통계에 따르면 2012년 기준 우리나라의 사과 재배면 적은 약 3 만 1 천 ha, 생산량은 약 39 만 톤으로 나타났다(3). 사과는 청량감과 산뜻한 맛뿐만 아니라 피로회복, 식욕증 진, 설사나 변비 및 소화불량 개선 등에 효과가 있으며, 다양한 무기질, 비타민이 함유되어 있어 우리나라 소비자 들에게 꾸준히 소비되는 과일이다(4).

*Corresponding author. E-mail : sskim@kfri.re.kr Phone : 82-31-780-9042, Fax : 82-31-780-9059
일반적으로 우리나라 소비자들은 과실을 구입할 때 가격 보다는 품질을 우선적으로 고려하는 것으로 알려져 있는데 (5), 그 중에서도 사과와 배는 그 크기가 클수록 소비자 선호도가 높고 시장가격도 높게 형성된다(6). 일본의 경우 에도 크기가 더 큰 사과를 선호하는 것으로 알려져 있다(7) 그러나 소비자들이 과실 구입 시 크기를 우선적으로 고려하 는 비율은 가정용이 $1.6 \%$, 선물용이 $13.6 \%$ 로 상대적으로 선물용으로 구입할 때 크기를 고려하는 비중이 훨씬 높다 (8). 이는 사과의 크기는 소비자들이 실제 본인을 위해 혹은 가족들을 위해 구입할 때보다 선물용이나 제수용에 중요한 영향을 미치는 것으로 볼 수 있다.

소비자들이 원하는 특성을 지닌, 특히 소비자들이 원하 
는 크기의 사과 생산은 국내산 사과 수요 및 소비를 증가시 켜 경쟁력을 향상시킬 수 있을 것이나 아직 이에 대한 연구 는 미흡한 실정이다. 사과의 소비자 검사에 대한 기존 연구 를 살펴보면 Cho 등(9)은 소비자 기호도 및 인지도 조사를 하였으며, Choi와 Lee(1)는 사과 소비행태나 이용실태 조 사, $\operatorname{Kim}$ 과 $\operatorname{Park}(6)$ 은 과실 크기에 대한 소비자 선호 변화 전망에 대한 연구 등이 있다.

국내의 경우, 소비자들이 실제 사과 시료를 보고, 맛보며 평가한 자료는 찾아보기 힘들다. 외국의 경우, Bonany 등 (10)은 여러 기호계층을 만족시키는 새롭고 향상된 품질의 사과 품종이 있다면 사과소비를 증가시킬 것이라는 가정 하에 유럽 7개국 대상, 총 4,290명의 소비자를 대상으로 11 개 사과 품종(신 품종 8개, 기존 품종 3 개)에 대한 소비자 검사 및 훈련된 패널에 의한 감각검사를 수행하였다. 그 결과, 소비자들이 속한 국가와 사과품종, 사과품종과 소비 자 연령대, 사과품종과 소비자 성별간 상호영향이 있었음 을 발표하여, 소비자 기호도는 여러 인자에 의해 영향 받음 을 보여 주었다. 최근 Seppa 등(11)은 104명의 소비자를 대상으로 6 개의 특성(푸석푸석한-아삭한:mealy-crispy, 단 맛이 없는-단맛의:not sweet-sweet, 붉지 않은-붉은; not red-red, 연한-단단한; soft-firm, 녹색이 아닌-녹색의: not green-green, 신맛이 없는-신맛의: not sour-sour)에 대한 사 과의 이상적인 정도를 7 항목척도를 이용하여 평가하였다. 비록 적은 수의 소비자이지만, Seppa 등(11)은 104명 소비 자들의 이상적인 특성평가결과에 의해 소비자들을 3 group(단맛, 신맛, 단맛-신맛 그룹)으로 나눌 수 있었다. 그 룹 1 의 25 명은 달고 부드러운 사과를, 그룹 2 의 34 명은 신맛이 강하고 단단한 조직감을 가진 사과를 그룹 3 의 45 명 은 중간정도의 단맛과 신맛을 지닌 사과를 이상적인 사과로 생각하는 그룹이었다. 그러나 국내 유통사과의 가격에 영 향을 주는 사과 크기에 대한 소비자 의견 혹은 소비자들이 생각하는 이상적인 사과 크기에 관한 내용은 국내외 연구에 서 찾아보기 힘들다.

국내 유통되는 사과 중 가장 높은 비율을 차지하고 있는 품종은 후지로, 2012년 기준 충북 영주지역에서 약 $67 \%$, 청송에서는 약 $75 \%$ 의 농가에서 재배되고 있다(12). 국내 사과는 $15 \mathrm{~kg}$ 단위 박스 당 개수(30 39개, 3D; 40 49개, $4 \mathrm{D}$; 50 59개, 5D; 60 69개, 6D; 70 79개, 7D; 80 89개, 8D) 로 선별되어 유통되고 있으며, 크기가 클수록 높은 가격에 유통되고 있다(6).

최근 사회구조의 변화에 따른 핵가족화, 일인가구의 증 가에 따라 소비자들이 원하는 특성이 변하고 있으며, 관련 업계도 소비자 요구에 따라 제품 특성을 달리하여 생산하고 있다. 이러한 추세는 공산품뿐만 아니라 농산물의 경우도 예외가 될 수 없다. 예를 들어 최근 농촌진흥청에서는 가족 구성원수의 감소 및 과일 소비확대를 위해 작은 크기의 사과 품종을 개발하여 보급을 확대하고 있다(13). 그러나
소비자들이 원하는 크기를 포함한 감각적 특성에 대한 연구 는 찾아보기 힘들다.

따라서 본 연구에서는 소비자들이 원하는 크기 및 사과 의 소비자 기호도에 결정적인 특성들을 분석하고자 현재 국내 생산 유통되는 주된 품종인 후지 2품종(일반후지, 로 얄후지) 크기 별 사과의 소비자 검사를 수행하였으며, 본 실험에 사용된 사과시료의 품질정도를 나타내는 객관적인 지표로서 이화학적 특성 분석을 수행하였다. 부가적으로는 소비자들이 원하는 사과의 특성분석을 위해 소비자들이 생각하는 이상적인 사과 특성과 실제 사과의 특성을 비교 분석하였다.

\section{재료 및 방법}

\section{실험재료}

본 실험에 사용된 사과 시료는 2012년산 2품종(일반후 지, 로얄후지), 크기별(3D : 30 39개/15 kg; 4D : 40 49개 $/ 15 \mathrm{~kg} ; 5 \mathrm{D}: 50 \sim 59$ 개/ $15 \mathrm{~kg} ; 6 \mathrm{D}: 60 \sim 69$ 개/ $15 \mathrm{~kg} ; 7 \mathrm{D}$ : 70 79개/15 kg; 8D : 80 89개/15 kg) 6종, 총 12종으로 충북농협사업단에서 구입하였다. 시료가 든 $5 \mathrm{~kg}$ 박스 째 비닐로 밀봉 포장하여 $0^{\circ} \mathrm{C}$ 저장고에 보관하며 사용하였다.

\section{사과의 이화학적 특성}

사과의 부피와 무게 및 비용적은 volscan profiler (VSP600, Stable Micro System Ltd., Haslemere, England)를 이용하여 측정하였다. 사과의 색도 $(\mathrm{L}, \mathrm{a}, \mathrm{b})$ 는 사과를 4 등분 하여 마주보는 2 조각은 껍질을 제거한 과육을, 나머지 2 조 각은 껍질의 색도를 측정하였다. 사과의 상부, 중부, 하부 과육과 껍질의 색도 $(\mathrm{L}, \mathrm{a}, \mathrm{b})$ 는 spectrophotometer(CM-700d, KONICA Minolta, Tokyo, Japan)을 사용하여 측정하였다. 색도 측정 후 fruit hardness tester(FHM-5, TAKEMURA Denki Manufacture Co., Tokyo, Japan)를 사용하여 사과의 상부, 중부, 하부의 껍질 유무에 따른 경도를 측정하였다. 사과의 당도, $\mathrm{pH}$, 산도 측정은 $\mathrm{Lee}$ 등(14)에 따라 수행하 였다. 사과 과육부분을 믹서기(HM-700, Hichen, Hwaseong, Korea)로 2 분간 갈아 거즈로 착즙한 후 digital refractometer (PR-32a, ATAGO, Tokyo, Japan)로 당도( ${ }^{\circ}$ Brix)를 측정하였 다. 사과의 $\mathrm{pH}$ 는 착즙된 과즙을 $\mathrm{pH}$ meter(Orion 2-star plus pH meter, Thermo Fisher Scientific Inc., Beverly, MA, USA) 를 사용하여 측정하였으며 사과의 산도는 착즙된 과즙을 $0.1 \mathrm{~N} \mathrm{NaOH}$ 용액으로 $\mathrm{pH} 8.2$ 가 될 때까지 적정하여 소모된 $\mathrm{NaOH}$ 의 양 $(\mathrm{mL})$ 을 malic acid의 양으로 환산하여 산출하 였다.

\section{소비자검사용 시료 준비}

본 실험의 소비자검사는 모든 패널요원에게 동일한 조건 
의 시료를 제공하기 위하여, 외관 평가용 사과시료는 유사 자연광의 light box(Super Light-VI, Boteck, Gunpo, Korea)에 제시하였으며, 향, 맛, 조직감 및 전반적인 기호도는 일정한 크기 $(20 \times 20 \mathrm{~mm}$, 지름 $\times$ 높이 $)$ 의 과육 3 조각을 제시하여 평 가하도록 하였다. 사과 시료는 사과씨 제거기(apple core, Cuisipro, Ontario, Canada)를 이용하여 사과씨를 제거한 뒤 수평으로 $20 \mathrm{~mm}$ 간격으로 잘라 사과씨 제거기를 사용하여 일정한 원통형 시료를 준비하였다. 소비자검사 시 사과의 갈변을 막기 위해 Corollaro 등(15)의 방법에 따라 citric acid $0.2 \%$, ascorbic acid $0.2 \%$, calcium chloride $0.5 \%$ 용액에 사과 조각을 담갔다가 바로 꺼내어 약 10 분간 체반에 받쳐 물기 를 제거하고 검사 전까지 밀폐용기에 담아 냉장보관 하였 다. 평가 시 모든 사과시료는 과육 3조각을 접시(지름 14 $\mathrm{cm})$ 에 담아 세 자리 무작위수로 coding 하여 패널들에게 제시하였다.

\section{소비자검사}

본 소비자 검사에는 사과를 좋아하며 서울 및 경기지역 에 거주하고, 본 검사에 대한 흥미와 참여할 시간적 여유 및 의사를 지닌 20 40대 소비자 100명이 참여하였다. 소비 자 검사는 컴퓨터가 설치된 개별 부스에서 진행하였다. 소 비자들은 사과시료를 평가하기 전 사과의 붉은색, 윤기, 표면 거칠음성, 사과향, 사과맛, 단맛, 신맛, 경도, 아삭거림 성, 다즙성, 씹는 동안의 질김성에 대해 소비자들이 생각하 는 이상적인 정도를 7 항목척도 $(1=$ 대단히 약하다, $7=$ 대단 히 강하다)에 표시하였다.

사과 시료는 한 번에 한 시료씩 랜덤화된 순서로 제시하 여 사과에 대한 외관, 향, 맛, 조직감, 전반적인 기호도를 9 항목척도( $1=$ 매우 싫어한다, $9=$ 매우 좋아한다)에 의해 평 가하였다. 지불의향가격(willingness to pay, WTP)은 일반적 으로 유통되는 $5 \mathrm{~kg}$ 단위 박스 당 가격을 30,000 원 $/ 5 \mathrm{~kg}$ 로 제시한 후, 각 평가시료의 지불의향가격을 평가하도록 하였다. 소비자들은 각 사과시료에 대한 구매의향(purchase intent, PI)은 5항목 척도 $(1=$ 확실히 구입하지 않겠다, $2=$ 구입 하지 않겠다, $3=$ 구입할지 안할지 모르겠다, $4=$ 구입하겠다, $5=$ 확실히 구입하겠다)에 의해 평가하였으며, 각 사과 시료 에 대한 구매의향 $(\%)$ 은 전체소비자 중 '구입 하겠다' 와 ‘확실히 구입하겠다'를 선택한 소비자들의 비율로 하였다.

소비자들은 사과에 대한 기호도 이외에, 사과 평가전에 이상적인 정도를 표시하였던 감각특성들(크기, 붉은색, 윤 기, 표면거칠음성, 사과향, 사과맛, 단맛, 신맛, 경도, 아삭거 림성, 다즙성, 씹는동안의 질김성)의 강도를 평가하였다. 각 소비자 패널은 1회 패널당, 6시료(한 품종 내 크기 별 6시료)를 평가하였으며, 모든 소비자들은 2회의 패널에 참 석하여 사과 2 품종 별 6 시료씩, 총 12 개의 시료를 평가하였 다. 소비자들은 한 번에 한 시료를 랜덤순서에 의해 제시받 아 평가하였으며, 다음 시료가 제시되기 전 평가된 시료는
모두 수거하여 평가 자료의 수정을 허용되지 않았다. 사과 의 소비자 검사는 2013년 6월 26일에서 2013년 7월 5일 사이에 수행하였다.

\section{통계분석}

본 연구에서 측정한 각 특성에서 시료 간 차이 여부를 알아보기 위하여 SAS 9.2(16)를 이용하여 분산분석을 수행 하였다. 그 결과, 시료 간 차이가 있는 경우 $\mathrm{SNK}$ (Student Newman Keul's) 다중비교를 하여 시료 간 평균값을 비교하 였다. 사과의 전반적인 기호도에 대한 외관, 향, 맛, 조직감 기호도의 기여도를 위해 전반적인 기호도(종속변수)와 외 관, 향, 맛, 조직감의 기호도(독립변수)과의 다중 회귀분석 을 수행하였다. 사과의 기호도 결정인자를 도출하기 위하 여 사과의 이화학 특성, 소비자 감각특성 및 소비자 기호도 와의 상관분석을 하였으며, 본 실험결과를 요약하기 위해 Xlstat(17)을 이용하여 주성분 분석(principal component analysis, PCA)를 하였다.

\section{결과 및 고찰}

사과의 이화학 특성

품종 및 크기 별 사과의 부피, 무게, 비용적 분석 결과는 Table 1에 있다. 부피와 무게 및 비용적은 3D에서 8D 순으 로 작아졌으며 비용적은 비교적 부피와 무게가 클수록 높은

Table 1. Physicochemical characteristics ${ }^{1)}$ of apple by cultivar and size of apple

\begin{tabular}{|c|c|c|c|c|c|}
\hline Cultivar & $\mathrm{Size}^{2)}$ & $\begin{array}{l}\text { Volume }^{* * *} \\
(\mathrm{~mL})\end{array}$ & $\underset{\text { (g) }}{\text { Weigh }^{* * *}}$ & $\begin{array}{l}\text { Specific } \\
\text { volume } \\
(\mathrm{mL} / \mathrm{g})\end{array}$ & $\begin{array}{l}\text { Hardness }^{* * *} \\
\text { (peeled, Top) }\end{array}$ \\
\hline \multirow{6}{*}{ Fuji } & $3 \mathrm{D}$ & $479^{\mathrm{a}}$ & $409^{\mathrm{a}}$ & $1.18^{\mathrm{ab}}$ & $1.72^{\mathrm{a}}$ \\
\hline & $4 \mathrm{D}$ & $364^{d}$ & $314^{d}$ & $1.16^{\mathrm{abc}}$ & $1.62^{\mathrm{a}}$ \\
\hline & $5 \mathrm{D}$ & $304^{\mathrm{e}}$ & $267^{\mathrm{e}}$ & $1.15^{\text {bcd }}$ & $1.52^{\mathrm{ab}}$ \\
\hline & $6 \mathrm{D}$ & $277^{\mathrm{f}}$ & $245^{\mathrm{g}}$ & $1.17^{\mathrm{abc}}$ & $1.64^{\mathrm{a}}$ \\
\hline & 7D & $225^{g}$ & $198^{\mathrm{i}}$ & $1.13^{\mathrm{d}}$ & $1.38^{\mathrm{ab}}$ \\
\hline & $8 \mathrm{D}$ & $196^{\mathrm{i}}$ & $174^{\mathrm{k}}$ & $1.18^{\mathrm{a}}$ & $1.64^{\mathrm{a}}$ \\
\hline \multirow{6}{*}{$\begin{array}{c}\text { Royal } \\
\text { Fuji }\end{array}$} & $3 \mathrm{D}$ & $444^{b}$ & $375^{b}$ & $1.16^{\mathrm{abc}}$ & $1.22^{b}$ \\
\hline & $4 \mathrm{D}$ & $384^{\mathrm{c}}$ & $331^{c}$ & $1.15^{\mathrm{bcd}}$ & $1.44^{\mathrm{ab}}$ \\
\hline & $5 \mathrm{D}$ & $295^{\mathrm{e}}$ & $256^{\mathrm{f}}$ & $1.15^{\text {bdd }}$ & $1.27^{\mathrm{b}}$ \\
\hline & $6 \mathrm{D}$ & $276^{f}$ & $241^{g}$ & $1.15^{\mathrm{bcd}}$ & $1.53^{\mathrm{ab}}$ \\
\hline & 7D & $237^{g}$ & $208^{\mathrm{h}}$ & $1.14^{\mathrm{cd}}$ & $1.38^{\mathrm{ab}}$ \\
\hline & $8 \mathrm{D}$ & $209^{h}$ & $184^{j}$ & $1.14^{\mathrm{cd}}$ & $1.28^{b}$ \\
\hline
\end{tabular}

\footnotetext{
${ }^{1)}$ Mean values of three determinations

${ }^{2)}$ Size 3D: $30 \sim 39,4 \mathrm{D}: 40 \sim 49,5 \mathrm{D}: 50 \sim 59,6 \mathrm{D}: 60 \sim 69,7 \mathrm{D}: 70 \sim 79,8 \mathrm{D}: 80 \sim 89$ apples/15 kg

${ }^{* * *}$ Significantly differ at $\mathrm{p}=0.001$

${ }^{a b c}$ Values followed by the same letter within a column are not significantly different from each other.
} 

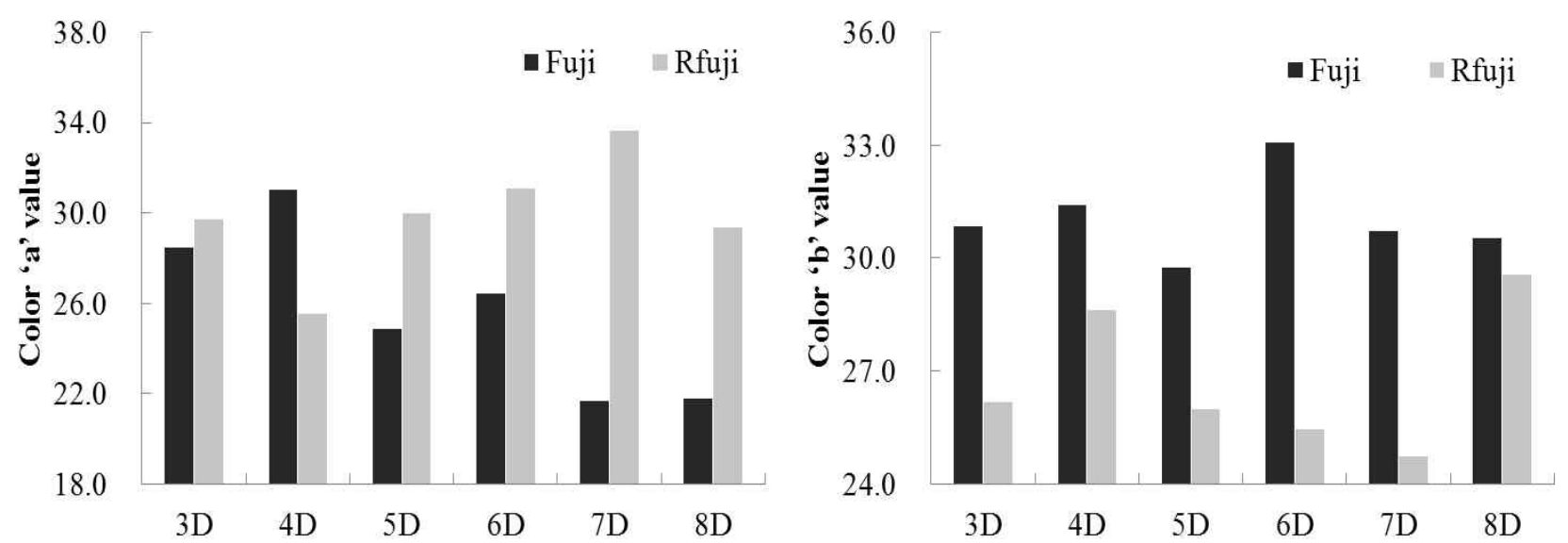

Fig. 1. Color 'a' value of unpeeled apple and color 'b' value of peeled Fuji and Royal Fuji (Rfuji) apple depending on size (3D: 30 39, 4D: 40 49, 5D: 50 59, 6D: 60 69, 7D: 70 79, 8D: 80 89 apples/15 kg).
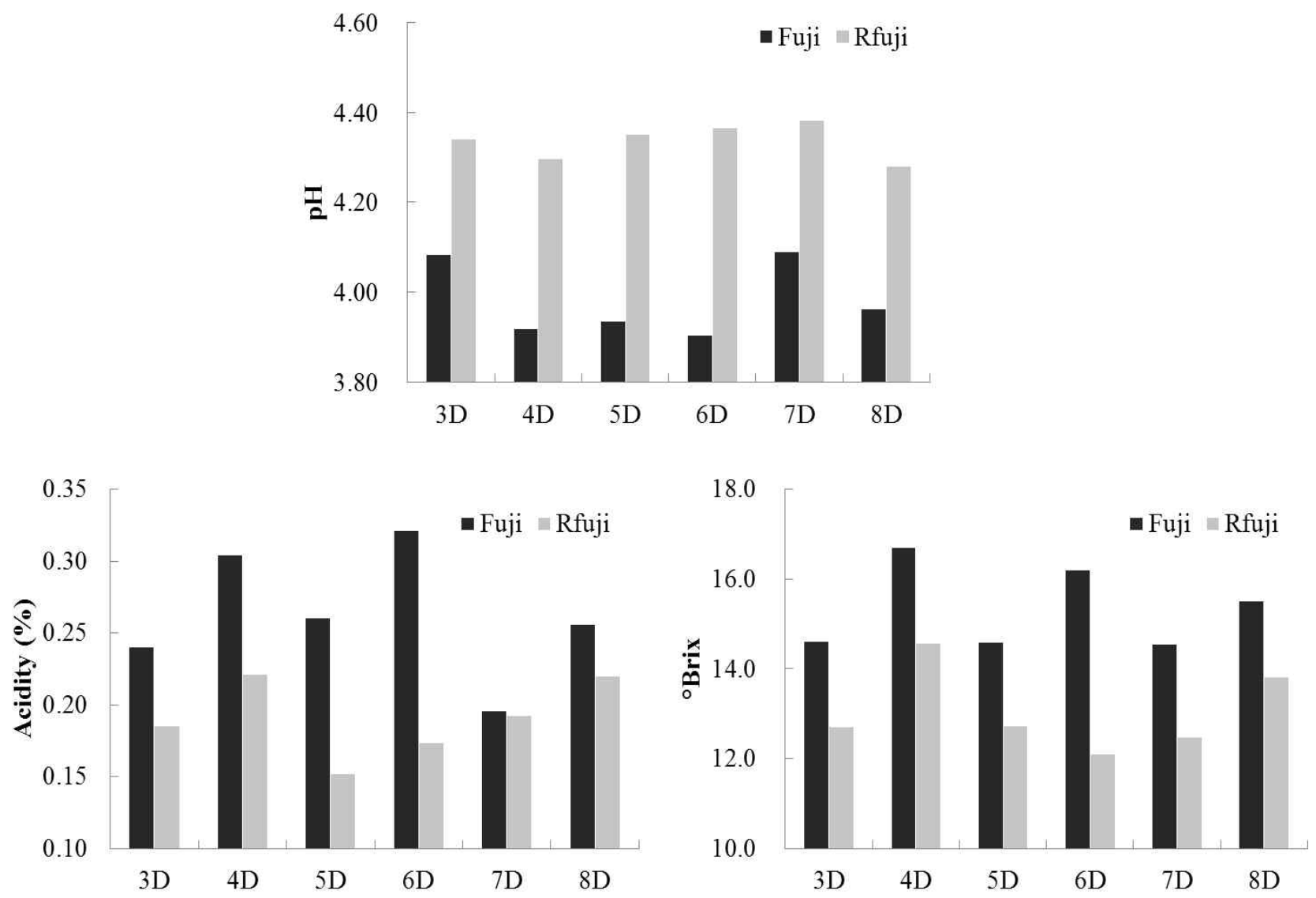

Fig. 2. The pH, acidity and soluble solids of Fuji and Royal Fuji (Rfuji) apple with various size (3D: 30 39, 4D: 40 49, 5D: 50 59, 6D: $60 \sim 69$, 7D: $70 \sim 79,8 \mathrm{D}: 80 \sim 89$ apples/15 kg)

경향이 있었다. 과육의 경도는 로얄후지에 비해 후지사과 가 높은 경향이 있었다. 품종 및 크기 별 사과 껍질의 색도 $\mathrm{a}$ 값 및 과육 색도 $\mathrm{b}$ 값은 Fig. 1에 있다. 붉은 정도를 나타내 는 색도 a 값의 경우 사과 껍질이 있을 때 $4 \mathrm{D}$ 경우를 제외하 고는 모두 로얄후지가 일반후지 품종에 비해 높았다. 사과
과육에서 노란 정도를 나타내는 색도 $\mathrm{b}$ 값은 전반적으로 로얄후지에 비해 후지사과가 높았다. 이화학 특성의 경우 (Fig. 2), 전반적으로 일반후지가 로얄후지에 비해 $\mathrm{pH}$ 는 낮 고 산도와 당도는 높았다. 국립농산물품질관리원의 농산물 표준규격에 따르면 후지 사과의 특 등급의 당도는 특 등급 
의 경우 14 이상, 상 등급은 12 이상(18)으로, 본 실험에 사용된 사과의 등급은 후지사과가 특급, 로얄후지는 상 등 급이었다.

\section{사과의 소비자 기호도}

본 연구의 소비자 기호도 검사에 참여한 소비자들의 남 자:여자의 비율은 12:87, 평균연령은 29.6세로, 주로 20 30 대의 사과를 좋아하는 여성이었다. 소비자들이 생각하는 이상적인 특성에 비교한 크기 별 후지사과, 로얄후지 사과 의 특성을 Fig. 3에 나타내었다. Worch 등(19)의 연구에서는 시료 평가 후 매번 이상적인 특성을 평가하도록 하였으나, 본 연구에서는 Seppa 등(11)의 연구에서와 같이 소비자들 이 생각하는 즉, 개념상의 이상적인 특성을 평가하도록 하
였다. 소비자들이 생각하는 이상적인 사과는 본 실험에서 평가한 사과보다 사과향, 사과맛, 단맛, 신맛, 경도, 아삭거 림성, 다즙성이 높은 사과였다. 본 연구에서 평가된 사과 시료 중 소비자들이 생각하는 이상적인 사과에 가장 가까운 것은 사과향, 사과맛, 단맛, 윤기, 다즙성이 강한 후지사과 $3 \mathrm{D}$ 였으며, 소비자들이 생각하는 이상적인 사과의 크기는 $4 \mathrm{D}$ 와 $5 \mathrm{D}$ 사이에 있었다. 즉, 사과크기 $4 \mathrm{D}$ 는 $40 \sim 49$ 개/ 15 $\mathrm{kg}, 5 \mathrm{D}$ 는 $50 \sim 59$ 개/ $15 \mathrm{~kg}$ 인 점을 감안하면 소비자가 생각 하는 사과의 이상적인 크기는 한 개당 $254 \mathrm{~g} \sim 375 \mathrm{~g}$ 사이의 무게를 지닌 사과였다.

품종 별 크기별 사과의 소비자 기호도 분석결과는 Table 2에 있으며, 전반적으로 로얄후지에 비해 일반후지의 기호 도가 더 높았다. 외관의 경우 소비자들은 후지사과 $3 \mathrm{D}$ 와

(A)

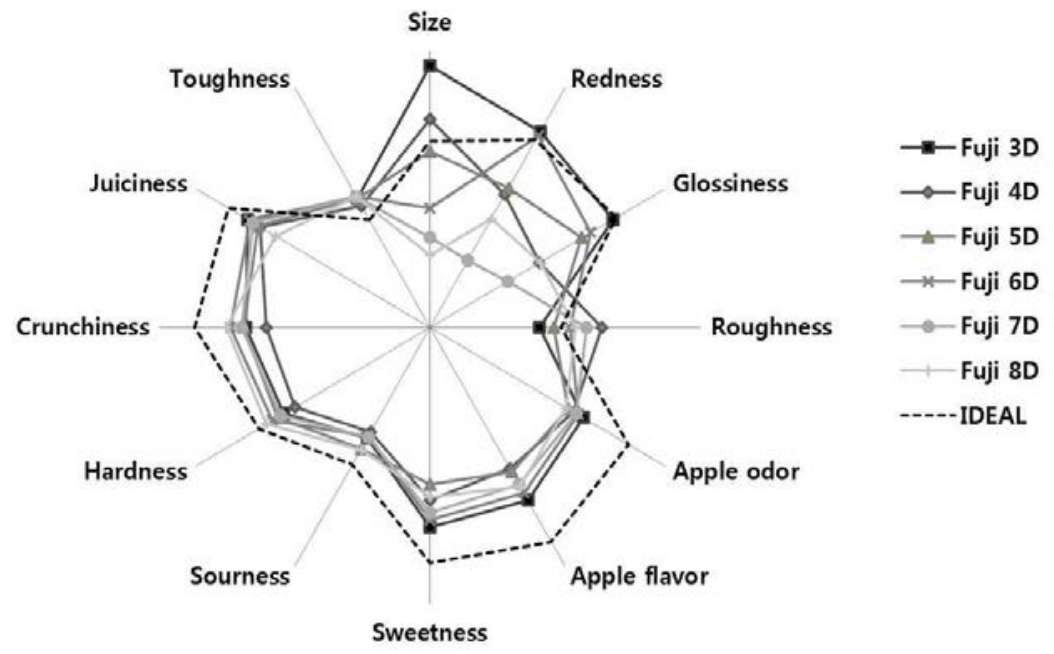

(B)

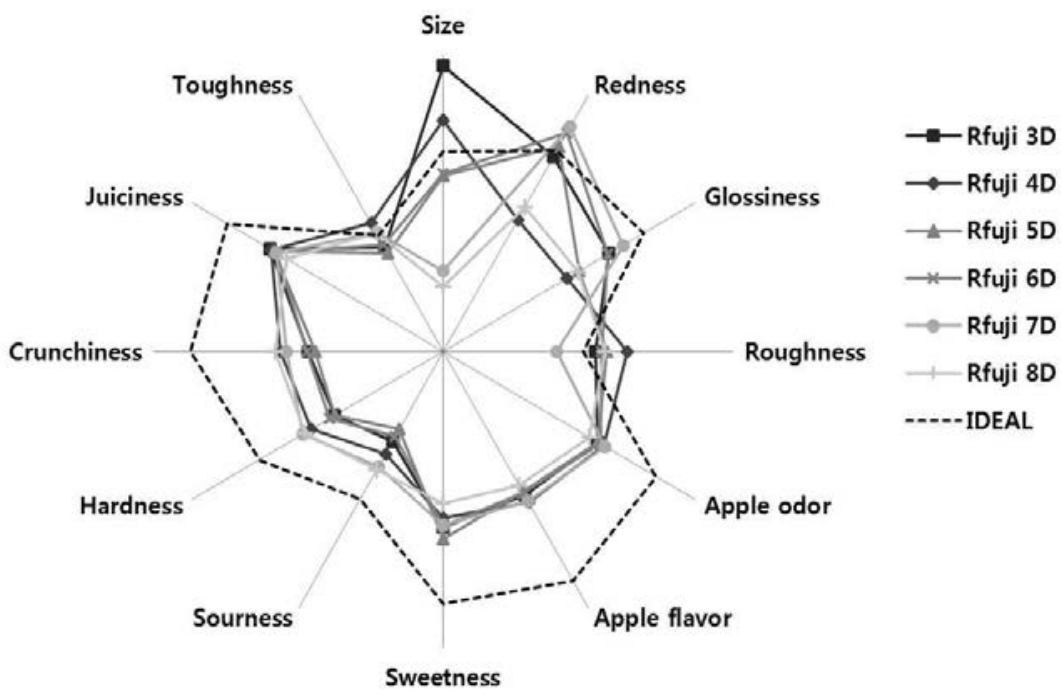

Fig. 3. Sensory characteristics of Fuji (A) and Royal Fuji (Rfuji) (B) apple with various size (3D: 30 39, 4D: 40 49, 5D: 50 59, 6D: 60 69, 7D: 70 79, 8D: 80 89 apples/15 kg) compared to ideal characteristics of apples. 
Table 2. Consumer acceptability ${ }^{1)}$ of apple depending on cultivar and size

\begin{tabular}{|c|c|c|c|c|c|c|}
\hline Cultivar & $\mathrm{Size}^{2)}$ & Appeatance $^{* * *}$ & Odor $^{* * *}$ & Taste $^{* * *}$ & Texture $^{* * *}$ & Overall $^{* * *}$ \\
\hline \multirow{6}{*}{ Fuji } & $3 \mathrm{D}$ & $7.88^{\mathrm{a}}$ & $6.60^{\mathrm{ab}}$ & $6.73^{\mathrm{a}}$ & $6.73^{a}$ & $6.70^{\mathrm{a}}$ \\
\hline & $4 \mathrm{D}$ & $6.47^{\mathrm{a}}$ & $6.13^{\mathrm{ab}}$ & $5.41^{\mathrm{cde}}$ & $5.68^{b}$ & $5.31^{\mathrm{de}}$ \\
\hline & $5 \mathrm{D}$ & $6.65^{\mathrm{bc}}$ & $6.22^{\mathrm{ab}}$ & $5.61^{\mathrm{dd}}$ & $6.46^{\mathrm{a}}$ & $5.63^{\text {cd }}$ \\
\hline & $6 \mathrm{D}$ & $7.07^{b}$ & $6.31^{\mathrm{ab}}$ & $6.51^{\mathrm{ab}}$ & $6.93^{\mathrm{a}}$ & $6.47^{\mathrm{ab}}$ \\
\hline & $7 \mathrm{D}$ & $4.32^{g}$ & $6.26^{\mathrm{ab}}$ & $5.92^{\mathrm{bc}}$ & $6.38^{\mathrm{a}}$ & $6.04^{\mathrm{bc}}$ \\
\hline & $8 \mathrm{D}$ & $5.06^{\mathrm{t}}$ & $6.12^{\mathrm{ab}}$ & $5.97^{\mathrm{bc}}$ & $6.54^{\mathrm{a}}$ & $6.09^{b c}$ \\
\hline \multirow{6}{*}{$\begin{array}{c}\text { Royal } \\
\text { Fuji }\end{array}$} & $3 \mathrm{D}$ & $6.97^{\mathrm{bc}}$ & $6.25^{\mathrm{ab}}$ & $4.85^{\mathrm{de}}$ & $4.90^{\text {cd }}$ & $4.87^{\mathrm{e}}$ \\
\hline & $4 \mathrm{D}$ & $5.95^{\mathrm{de}}$ & $6.21^{\mathrm{ab}}$ & $5.13^{\mathrm{de}}$ & $5.46^{b c}$ & $5.17^{\mathrm{de}}$ \\
\hline & $5 \mathrm{D}$ & $6.34^{\mathrm{de}}$ & $6.71^{a}$ & $4.97^{\mathrm{de}}$ & $4.54^{d}$ & $4.63^{\mathrm{e}}$ \\
\hline & $6 \mathrm{D}$ & $6.86^{b c}$ & $6.41^{\mathrm{ab}}$ & $5.13^{\mathrm{de}}$ & $4.84^{\mathrm{cd}}$ & $5.02^{\mathrm{de}}$ \\
\hline & $7 \mathrm{D}$ & $5.66^{\mathrm{e}}$ & $6.39^{\mathrm{ab}}$ & $5.17^{\mathrm{de}}$ & $5.18^{\text {bdd }}$ & $5.06^{\mathrm{de}}$ \\
\hline & $8 \mathrm{D}$ & $5.65^{\mathrm{e}}$ & $5.82^{\mathrm{b}}$ & $4.73^{\mathrm{e}}$ & $5.41^{\mathrm{bc}}$ & $4.71^{\mathrm{e}}$ \\
\hline \multicolumn{7}{|c|}{$\begin{array}{l}\text { 1) Mean values by } 100 \text { consumers } \\
\text { 2) Size 3D: } 30 \sim 39,4 \mathrm{D}: 40 \sim 49,5 \mathrm{D}: 50 \sim 59,6 \mathrm{D}: 60 \sim 69,7 \mathrm{D}: 70 \sim 79,8 \mathrm{D}: 80 \sim 89 \\
\text { apples } 15 \mathrm{~kg} \\
\text { *, Significantly differ at } \mathrm{p}=0.05, \mathrm{p}=0.001 \\
\text { abc Values followed by the same letter within a column are not significantly different } \\
\text { from each other. }\end{array}$} \\
\hline
\end{tabular}

$4 \mathrm{D}$ 크기를 선호하였으며, 로얄후지 $7 \mathrm{D}, 8 \mathrm{D}$ 에 대한 기호도 는 가장 낮았다. 향에서는 로얄후지 $5 \mathrm{D}$ 의 기호도가 가장 높았으며 로얄후지 $8 \mathrm{D}$ 는 가장 낮았다. 맛의 기호도는 후지 $3 \mathrm{D}$ 가 가장 높았으며 로얄후지 $8 \mathrm{D}$ 가 가장 낮았다. 조직감의 기호도는 $4 \mathrm{D}$ 를 제외한 후지사과 5 종의 기호도가 가장 높았 다. 전반적인 기호도는 후지 $3 \mathrm{D}$ 가 가장 높았다.

또한 사과의 외관, 향, 맛, 조직감의 기호도(독립변수)가 전반적인 기호도(종속변수)에 미치는 영향을 분석하기 위 하여 전반적인 기호도 $(\mathrm{y})$ 와 외관, 향, 맛, 조직감의 기호도 (x)간 회귀분석을 실시한 결과, 도출된 회귀식인 식 [1]에 의해 총 변량의 $86.1 \%$ 를 설명할 수 있었다. 전반적인 기호 도에 영향을 미치는 인자로는 맛의 기호도계수가 0.706 으 로 가장 높았으며 그 뒤로 조직감, 향, 외관의 기호도 순으로 나타났다. 본 실험결과 도출된 회귀식에서 외관의 계수크 기가 작은 것은 향, 맛, 조직감과 달리 외관의 기호도는 light box내에서 사과를 독립적으로 평가하어, 전반적인 기 호도에 대한 기여도가 낮았던 것으로 판단된다. 향후 시료 제시조건에 따른 전반적인 기호도에 대한 외관, 향, 맛, 조직 감의 기여도에 관한 확인실험이 필요할 것으로 사료된다.

$$
\begin{aligned}
& \text { Overall acceptability }=0.069-(0.005 \text { appearance })+ \\
& (0.022 \text { odor })+(0.706 \text { taste })+(0.245 \text { texture }) \quad\left(\mathrm{R}^{2}=0.86\right)
\end{aligned}
$$

사과의 소비자 기호도와 이화학 특성 및 감각특성 간 관계 소비자들이 평가한 사과 외관의 기호도 및 전반적인 기
호도를 사과의 이화학적 특성과 소비자들이 평가한 사과의 강도특성과 함께 상관분석을 하였다(Table 3). 사과 외관의 기호도는 소비자들이 외관으로 평가한 지불의향 가격, 구 매의향과 상관이 높았으며 전반적인 기호도는 지불의향 가격, 구매의향과 상관이 높게 나타나 일관성 있는 소비자 평가경향이 있음을 보여주었다.

사과 외관의 기호도는 이화학특성 중 크기 $(\mathrm{r}=0.727)$, 무 게 $(\mathrm{r}=0.734)$ 와 상관이 높았으며 소비자 감각 특성 중 윤기

Table 3. Correlation coefficient (r) between appearance acceptability or overall acceptability and physicochemical characteristics, sensory characteristics, purchase intent and willingness to pay for

\begin{tabular}{|c|c|c|}
\hline & $\begin{array}{l}\text { Appearance } \\
\text { acceptability }\end{array}$ & $\begin{array}{c}\text { Overall } \\
\text { acceptability }\end{array}$ \\
\hline \multicolumn{3}{|l|}{ Physicochemical characteristics } \\
\hline Volume & 0.727 & 0.110 \\
\hline Weigh & 0.734 & 0.123 \\
\hline Specific volume & 0.455 & 0.165 \\
\hline $\mathrm{pH}$ & -0.038 & -0.730 \\
\hline Acidity & 0.202 & 0.597 \\
\hline Brix & -0.034 & 0.624 \\
\hline Hardness (Flesh, Top) & 0.317 & 0.784 \\
\hline L (Skin, Top) & -0.555 & 0.646 \\
\hline a (Skin, Top) & 0.456 & -0.555 \\
\hline b (Skin, Top) & -0.351 & 0.794 \\
\hline L (Flesh, Top) & -0.299 & -0.524 \\
\hline a (Flesh, Top) & -0.088 & 0.564 \\
\hline b (Flesh, Top) & -0.003 & 0.737 \\
\hline \multicolumn{3}{|l|}{ Sensory characteristics by consumer } \\
\hline Size & 0.722 & 0.014 \\
\hline Redness & 0.730 & -0.164 \\
\hline Glossiness & 0.797 & 0.130 \\
\hline Surface roughness & -0.335 & -0.316 \\
\hline Apple odor & 0.381 & 0.279 \\
\hline Apple flavor & 0.129 & 0.984 \\
\hline Sweetness & 0.299 & 0.761 \\
\hline Sourness & -0.271 & 0.621 \\
\hline Hardness & -0.234 & 0.814 \\
\hline Crunchiness & -0.182 & 0.860 \\
\hline Juiciness & 0.343 & 0.771 \\
\hline Toughness during mastication & -0.187 & 0.843 \\
\hline (by appearance of whole & 0.968 & 0.185 \\
\hline Willingness to pay apple under light box) & 0.934 & -0.023 \\
\hline (by uniform size of apple & 0.180 & 0.934 \\
\hline Willingness to pay sample without skin) & 0.082 & 0.986 \\
\hline
\end{tabular}
apple 
$(\mathrm{r}=0.797)$, 붉은 정도 $(\mathrm{r}=0.730)$, 크기 $(\mathrm{r}=0.722)$ 와 관련이 높았 다. 즉, 외관 면에서 소비자들은 윤기와 붉은색이 강하고 크기가 큰 사과를 선호하였다. 본 연구결과는 Manalo(20)와 Skreli 및 Imami(21)의 연구에서 소비자들이 사과를 고를 때 크기가 크고, 붉은 색이 강한 사과를 좋아한다는 결과를 확인하였으며, 본 연구에서는 붉은색과 크기 외에 사과 외 관의 윤기를 중요한 특성으로 소비자들이 인지하고 있음을 보여주었다. 소비자에 의한 외관 기호도와 소비자가 평가 한 크기와의 상관계수(r)는 0.722 로서, 외관 기호도와 사과 의 이화학적 특성인 부피(r=0.727) 및 사과 무게 $(\mathrm{r}=0.734)$ 와 의 상관계수 크기와 비슷하게 나타나, 크기를 나타내는 이 화학적특성과 소비자에 의한 감각특성평가간의 일관성을 보여주었다.

소비자 기호도 결정인자로서, 소비자 기호도와 상관이 높은 이화학적 특성은 사과 상부의 껍질 및 과육의 색도 $\mathrm{b}$ 값(각각 $\mathrm{r}=0.794, \mathrm{r}=0.737)$, 과육의 경도( $\mathrm{r}=0.784), \mathrm{pH}$ $(\mathrm{r}=-0.730)$ 이었으며, 소비자들이 평가한 감각특성으로는 사 과맛 $(\mathrm{r}=0.984), \quad$ 아삭거림성 $(\mathrm{r}=0.860)$, 씹는동안 질김성 $(\mathrm{r}=0.843)$, 경도 $(\mathrm{r}=0.814)$, 다즙성 $(\mathrm{r}=0.771)$, 단맛 $(\mathrm{r}=0.761)$ 으 로 나타났다. 본 연구결과는 소비자들은 아삭하고 단맛의 사과를 좋아한다는 Manalo(20)의 연구 결과 외에 사과 특유 의 맛과 더불어 씹는 동안 느껴지는 조직감, 경도, 다즙성에 의해 복합적으로 사과의 소비자 기호도가 결정됨을 보여주 고 있다.

소비자들이 평가한 사과의 감각특성강도, 전반적인 기호 도, 지불의향가격(WTP) 및 구매의향(PI) 간의 주성분 분석 결과는 Fig. 4에 있다. 주성분 1은 총 변동의 $47.29 \%$, 주성분 2 는 $30.98 \%$, 즉, 주성분 1 과 주성분 2 에 의해 총변동의 $78.27 \%$ 를 설명할 수 있었다. 주성분 1 은 사과의 전반적인 기호도, 조직감의 기호도, 지불의향가격, 사과맛, 아삭거림 성, 질김성 등 사과의 향, 맛, 조직감과 관련 있었으며 주성 분 2 는 외관의 기호도, 외관으로 평가한 지불의향가격과 구매의향, 윤기, 붉은색, 크기와 같은 사과의 외관 및 사과 향과 관련이 있었다. 전반적인 기호도가 높은 후지 사과 $3 \mathrm{D}$ 와 $6 \mathrm{D}$ 가 주성분 $1(+)$, 주성분 $2(+)$ 방향에 위치하여 단맛 및 다즙성 방향과 일치하였다. 외관으로 평가한 사과의 구 매의향과 지불의향가격은 사과의 붉은 정도, 크기와 상관 이 있었는데, 소비자들은 외관으로 평가 시에는 로얄후지 $3 \mathrm{D}$ 를 가장 좋아하였다. 그러나 전반적인 기호도와 외관 특성 간 상관은 미미하였는데, 이는 전반적인 기호도 평가 시 외관특성이 배제된, 일정한 크기의 사과 과육만을 제시 하여 평가하였기 때문이라 판단된다. 즉, 시료에 대한 정보 없이 평가하는 경우 시료의 관능적 특성에만 의존하여 평가 한다는 Bower 등(22)의 연구결과에서와 같이, 본 연구의 전반적인 기호도는 외관에 대한 정보 없이, 향, 맛, 조직감에 의존하여 평가하였기 때문이라 사료된다.

전반적으로 본 연구결과는 소비자들이 원하는 사과의
크기는 유통되는 사과 크기 중 가장 큰 크기인 $3 \mathrm{D}$ 가 아닌 $4 \mathrm{D}$ 와 5D 사이로 소비자들은 크기가 클수록 소비자들이 선호하는 것이 아님을 보여주었다. 외관, 향, 맛, 조직감의 기호도 중 전반적인 기호도에 가장 큰 영향을 주는 특성은 맛의 기호도, 그 다음은 조직감의 기호도였으며, 향과 외관 의 기호도가 전반적인 기호도에 준 영향은 비교적 낮았다. 전반적인 기호도에 대한 외관의 기여도가 낮은 이유는 아마 도 본 실험에 사용된 모든 사과시료들은 외관적인 결점이 없는 선별된 사과였기 때문으로 판단된다. 사과의 기호도 결정인자로서 이화학적 특성으로는 낮은 $\mathrm{pH}$, 높은 당도, 과육 상부의 경도 및 과육 색도 $\mathrm{b}$ 값으로 나타났으며, 감각특 성으로는 높은 사과맛, 아삭거림성, 씹는동안 질김성, 경도, 단맛, 다즙성의 순으로 나타났다.

국내 후지사과 생산농가 및 관련 유통산업의 경쟁력 향 상을 위해서는 소비자들이 선호하는 특성을 지닌 사과의 생산 및 유통이 필수적이며, 본 연구결과는 소비자들이 선 호하는 후지사과의 특성은 중간크기(4D>, >5D)의 사과특 유의 맛 및 단맛이 강하고, 아삭거림성, 씹힘성, 경도 및 다즙성이 높으며, 객관적으로는 $\mathrm{pH}$ 가 낮고, 당도( $\left.{ }^{\circ} \mathrm{Brix}\right)$ 가 높고, 과육이 단단하며, 진한 노란(b value)색의 과육임을 보여주었다. 본 연구결과에서 보여준 소비자들이 선호하는 특성을 지닌 후지사과의 생산 및 유통에 의해 국내 사과소 비 증가, 나아가서는 국내 사과관련 업계의 경쟁력 향상이 기대된다.

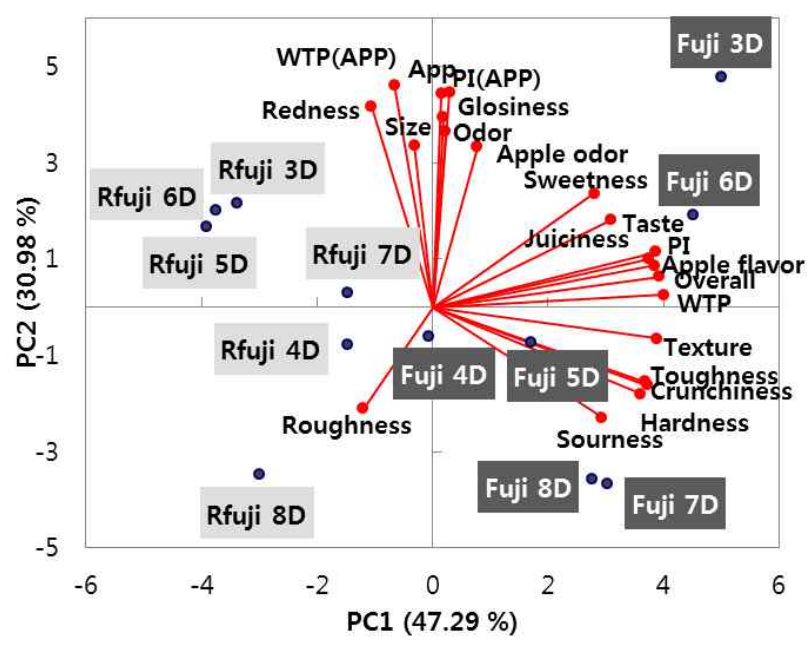

Fig. 4. Principal component (PC) analysis loading of the 12 apples and their consumer properties and willingness to pay (WTP), purchase intent (PI) in the PC 1 and PC 2 (3D: 30 39, 4D: 40 49, 5D: 50 59, 6D: $60 \sim 69$, 7D: 70 79, 8D: $80 \sim 89$ apples/15 kg, Fuji, Fuji apple; RFuji, Royal Fuji apple).

\section{요 약}

소비자들이 좋아하는 사과의 특성을 도출하고자 국내의 
주된 사과 2품종(일반후지, 로얄후지), 6크기별(3D : 30 39 개/15 kg; 4D : 40 49개/15 kg; 5D : $50 \sim 59$ 개/15 kg; 6D : 60 69개/15 kg; 7D : 70 79개/15 kg; 8D : 80 89개/15 $\mathrm{kg}$ ), 총 12 사과시료에 대한 이화학 특성분석 및 소비자검사 를 수행하였다. 사과의 이화학적특성분석 결과 일반후지 품종이 로얄후지 품종에 비해 $\mathrm{pH}$, 껍질의 색도 $\mathrm{a}$ 값(붉은 정도)는 낮고 경도, 산도, 당도, 과육의 색도 $\mathrm{b}$ 값(노란 정도) 이 높은 경향이 있었다. 소비자들이 생각하는 이상적인 사 과의 특성은 본 실험에 사용된 사과보다 사과향, 사과맛, 신맛, 경도, 아삭거림성, 다즙성이 높았으며, 이상적인 사과 의 크기는 4D 5D사이로서 한 개당 $254 \mathrm{~g} \sim 375 \mathrm{~g}$ 사이의 무게를 지닌 사과였다. 전반적으로 로얄후지에 비해 일반 후지의 기호도가 더 높았다. 기호도 항목(외관, 향, 맛, 조직 감)중, 사과의 전반적인 기호도에 가장 상관이 높았던 항목 은 맛의 기호도였으며, 조직감, 향, 외관의 기호도 순으로 나타났다. 전반적인 기호도와 외관 기호도간 낮은 상관계 수는 외관 기호도만 독립적으로 평가한 본 실험 방법에 일부 기인하였다고 사료되며 이에 대한 확인을 위해 향후 시료제시방법에 따른 추가적인 연구가 필요하다. 소비자들 은 외관면에서 윤기 및 붉은색이 강한 큰 사과를 좋아하였 으며, 외관에 대한 정보 없이 일정한 크기의 과육만을 제공 하여 평가한 소비자 기호도와 상관이 높은 이화학특성은 사과 상부의 껍질 및 과육의 색도 $\mathrm{b}$ 값(각각 $\mathrm{r}=0.794$, $\mathrm{r}=0.737)$, 과육의 경도 $(\mathrm{r}=0.784), \mathrm{pH}(\mathrm{r}=-0.730)$ 이었으며, 감 각특성으로는 사과맛 $(\mathrm{r}=0.984)$, 아삭거림성 $(\mathrm{r}=0.860)$, 씹는 동안 질김성 $(\mathrm{r}=0.843)$, 경도 $(\mathrm{r}=0.814)$, 다즙성 $(\mathrm{r}=0.771)$, 단맛 $(\mathrm{r}=0.761)$ 으로 나타났다. 즉, 본 연구결과는 소비자들이 선 호하는 후지사과의 특성은 중간크기(4D>, >5D)의 사과특 유의 맛 및 단맛이 강하고, 아삭거림성, 씹힘성, 경도 및 다즙성이 높으며, 객관적으로는 $\mathrm{pH}$ 가 낮고, 당도 $\left({ }^{\circ} \mathrm{Brix}\right)$ 가 높고, 과육이 단단하며, 진한 노란(b value)색의 과육임을 보여주었다.

\section{References}

1. Choi YH, Lee SJ (2005) A survey on uses, preference and recognition of apple. Korean J Food Culture, 20, 204-213

2. Chung HS, Moon KD, Choi JU (1999) Processing and MAP(modified atmosphere packaging) storage of fresh-cut apple using CA stored apples. Korean J Postharvest Sci Technol, 6, 351-356

3. MAFRA (2013) Agriculture, food and rural affairs statistics yearbook. Ministry of Agriculture, Food and Rural Affairs, Sejong-si, Korea, p 88, p 116

4. Hwang TY, Son SM, Lee CY, Moon KD (2001) Quality changes of fresh-cut packaged fuji apples during storage. Korean J Food Sci Technol, 33, 469-473

5. KREI (2007) Agricultural outlook 2007. Korean Rural Economic Institute, Seoul, Korea, p 710

6. Kim KP, Park MS (2007) Consumer preferences for fruit size and their implication. Korean J Food Marketing Economics, 24, 26-39

7. Kajikawa C (1998) Quality level and price in Japanese apple market. Agribusiness, 14, 227-234

8. Kim KP, Kim YH, Park JH (2004) An analysis on the change of consumer's fruit purchasing behavior. J Rural Development, 27, 55-66

9. Cho SD, Kim DM, Kim GH (2008) Survey on consumer perceptions of the sensory quality attributes of apple. Korean J Food Preserv, 15, 810-815

10. Bonany J, Buehler A, Carbo J, Codarin S, Donati F, Echeverria G, Egger S, Guerra W, Hilaire C, Holler I, Iglesias I, Jesionkowska K, Konopacka D, Kruczynska D, Matinelli A, Pitiot S, Sansavini S, Stehr R, Schoorl F (2013) Consumer eating quality acceptance of new apple varieties in different European countries. Food Qual Pref, 30, 250-259

11. Seppa L, Railio J, Vehkalahti K, Tahvonen R, Tuorila $H$ (2013) Hedonic response $s$ and individual definitions if an ideal apple as predictors of choice. J Sensory Studies, 28, 346-357

12. aT (2013) Survey on major agricultural products in 2012 Korea Agro-Fisheries \& Food Trade Corporation, Seoul, Korea, p 662

13. Park SG (2013) Expansion of distribution for medium sized apple and pear breeds. Nongminnews October 18, Seoul, Korea p 10

14. Lee JW, Kim SH, Hong SI, Jeong MC, Park HW, Kim DM (2003) Internal and external quality of fuji apples. Korean J Food Preserv, 10, 47-53

15. Corollaro ML, Endrizzi I, Bertolini A, Aprea E, Dematte ML, Costa F, Biasioli F, Gaspen F (2013) Sensory profiling of apple: methodological aspects, cultivar characterization and postharvest changes. Postharvest Biol Tec, 77, 111-120

16. SAS (2008) SAS/STAT 9.2 User's Guide, SAS Institute Inc., Cary, NC, USA

17. Addinsoft (2014) Xlstat, Data analysis and statistics with MS excel. Addinsoft, Paris, France

18. NAQS (2013) Agricultural standards notice no. 2013-42. National Agricultural Products Quality Management Service, Gimcheon-si, Korea, p 15 
19. Worch T, Le S, Punter P, Pages J (2013) Ideal profile method (IPM): The ins and outs. Food Qual Pref, 28, 45-49

20. Manalo AB (1990) Assessing the importance of apple attributes: An agricultural application of conjoint analysis. Northeastern J Agric Res Econ, 19, 118-124

21. Skreli E, Imami D (2012) Analyzing consumers' preference for apple attributes in Tirana, Albania.
International Food and Agribusiness Management Review, 15, 137-156

22. Bower JA, Saadat MA, Whitten C (2003) Effect of liking, information and consumer characteristics on purchase intention and willingness to pay more for a fat spread with a proven health benefit. Food Qual Pref, 14, 65-74

(접수 2014년 5월 15일 수정 2014년 8월 29일 채택 2014년 9월 16일) 